\title{
CARACTERIZAÇÃO DOS CAFÉS PRODUZIDOS EM SOLOS BASÁLTICOS E ARENOSOS DO PARANÁ
}

\section{CHARACTERIZATION OF THE COFFEE PRODUCED IN BASALTIC AND ARENACEOUS SOIL OF THE PARANÁ STATE}

\author{
Carla Adriana Pizarro Schmidt ${ }^{1}$, Édison Miglioranza ${ }^{2}$; Aline de Oliveira Garcia ${ }^{3}$; Eric Batista Ferreira ${ }^{4}$ \\ ${ }^{1}$ Universidade Tecnológica Federal do Paraná - UTFPR - Medianeira - Brasil carlaschmidt@utfpr.edu.br \\ ${ }^{2}$ Universidade Estadual de Londrina - UEL - Londrina - Brasil \\ ${ }^{3}$ Instituto de Tecnologia de Alimentos - ITAL - Campinas - Brasil \\ ${ }^{4}$ Universidade Federal de Alfenas (UNIFAL-MG) - Alfenas - Brasil
}

\begin{abstract}
Resumo
A logística de comercialização do Paraná, a semelhança do que ocorre com as regiões produtoras de vinho, propõe que os cafés produzidos no estado sejam separados segundo sua região de origem. O que caracteriza a cafeicultura paranaense é o fato de que ela está implantada em solos de origem basáltica e em solos oriundos do arenito Caiuá. Este trabalho foi desenvolvido buscando a caracterização fisico-química dos grãos e sensorial das bebidas dos cafés produzidos nos solos basálticos e sedimentares. Foram avaliados grãos da cultivar IAPAR 59, tendo sido realizadas as análises: classificação do tipo, cinzas, umidade, proteínas, lipídeos, fibras totais, acidez titulável, pH e índice de coloração. A análise descritiva quantitativa ( $A D Q \circledR)$, foi feita por oito provadores treinados, para duas amostras compostas de grãos colhidos em solos arenoso e argilosos com duas intensidades de torras, obtendo-se notas em escala de um a dez para atributos como: fragrância, aroma, defeitos, acidez, amargor, sabor, sabor residual, adstringência, corpo e qualidade global. Os provadores treinados não detectaram diferenças entre os cafés oriundos das diferentes formações dos solos em nenhuma das intensidades de torra. Na torra escura os provadores detectaram aumento no amargor e na adstringência e redução no sabor, acidez, aroma $e$ fragrância. Independentemente da textura ou origem do solo os cafés apresentaram bom corpo $e$ baixa acidez. O teor de lipídios foi menor no café produzido no arenito.
\end{abstract}

Palavras-chave: Coffea arábica; nitossolo; marketing; qualidade de bebida.

\section{Introdução}

Segundo Leroy et al., (2006), o café é um produto agrícola valorizado devido seus atributos qualitativos, e os preços obtidos são maiores à medida que se aumente essa qualidade, que é dependente da genética e de todas as etapas da produção do café. 
O café produzido no Paraná é seguramente um dos bons cafés do Brasil. É cultivado nas antigas terras roxas (Nitossolo) e nos solos do arenito Caiuá sendo a bebida predominantemente padrão duro a mole (DALBERTO et al., 2000).

A topografia do Paraná consiste de uma estreita faixa costeira ao longo da Costa Atlântica, separada do interior do estado pelas montanhas da Serra do Mar. Ao ocidente da Serra do Mar ocorre a formação de três planaltos sucessivos e, nessa situação, mais da metade da superfície do estado encontra-se abaixo dos $700 \mathrm{~m}$ de altitude (MUZILLI, 2010).

No estado, dois grandes grupos de solos são facilmente diferenciados. O primeiro, com textura arenosa média, proveniente do arenito, denominado formação Caiuá e o segundo mais argiloso originado do grande derrame de basalto, denominado formação Serra Geral (EMBRAPA, 1984). A diversidade desses solos está estreitamente ligada ao clima, relevo e geologia dos locais onde eles se originaram (NAKASHIMA e NÓBREGA, 2003).

$\mathrm{O}$ arenito Caiuá encontra-se na região noroeste do estado onde recobre área aproximada de $25.000 \mathrm{Km}^{2}$. Sua formação é constituída predominantemente por arenitos de frações médias, finas a muito finas, com coloração vermelho-arroxeado a vermelho-escuro, e quando alterado apresenta tons amarelados (GASPARETTO e SOUZA, 2003).

O basalto cobre cerca de $40 \%$ da superfície do estado, é estimado em cerca de $780.000 \mathrm{~km}^{2}$, recebendo a denominação de formação Serra Geral da Bacia do Paraná. O intemperismo desta rocha forma o Nitossolo, que é muito fértil. Esta condição favorável viabilizou desenvolvimento de imensa plantação de café, constituindo uma importante riqueza do Brasil (MUZILLI, 2007; MOTOKI et al., 2004; NARDY et al., 2005).

Embora tenha sido o Nitossolo o elemento básico responsável pela introdução e desenvolvimento da cafeicultura no Norte do Paraná, sua ocorrência não delimitou a expansão da cultura cafeeira para o noroeste atingindo as regiões do arenito. Um limite bem mais rígido, foi imposto pelo clima no sentido do sul do estado, devido à redução da temperatura e a maior frequência de geadas que tornam o cultivo do café impraticável (MULLER, 2001).

De acordo com Armando Androcioli Filho, pesquisador do Instituto Agronômico do Paraná (IAPAR), 80\% dos novos plantios de café têm sido feitos com a cultivar Iapar 59 (O CAFEZAL, 2008). Ela tem como principal característica a resistência à ferrugem do cafeeiro, o que elimina a necessidade de produtos químicos para o controle da doença, propiciando economia de investimentos e evitando a contaminação do meio ambiente (SERA et al., 1996).

Essa variedade tem apresentado produtividade mais elevada que as demais recomendadas para o Paraná nos últimos anos segundo AIRES (2007) engenheiro agrônomo da Cooperativa de Cafeicultores de Maringá (COCAMAR), sendo ideal para plantios adensados e super adensados, os 
quais, de acordo com Paulo Franzini, já ocupam 55\% da área plantada e correspondem a 66\% da produção de café do Paraná (AEN, 2006).

Os frutos são vermelhos, os brotos de cor predominantemente bronze, com pequeno percentual de verdes; os grãos apresentam peneira média 16; a qualidade de bebida é semelhante às cultivares em uso; possui precocidade de produção e longevidade produtiva de no mínimo 10 anos, com bom vigor vegetativo (SERA et al., 1996).

O objetivo deste trabalho foi avaliar a qualidade sensorial da bebida e a composição fisicoquímica da 'IAPAR 59', cultivada em solos, originados do basalto e do arenito, os quais mesmo sob condições climáticas semelhantes apresentam particularidades, em suas características químicas, físicas, de balanço de água e de energia, entre outros, que influem diretamente sobre o crescimento e o desenvolvimento dos frutos.

\section{Material e Métodos}

Foram avaliadas amostras de café, da cultivar IAPAR 59, colhidas em sítios e fazendas produtoras de café localizadas nos municípios paranaenses Lupionópolis, Centenário do Sul, Miraselva, Prado Ferreira, Astorga, Munhoz de Melo e Londrina, todos relacionados como municípios aptos ao cultivo (MITIDIERI, 2007) e que, com exceção de Londrina, possuem os dois tipos de materiais de origem dos solos (basalto e arenito). Segundo a classificação de Köppen, todas se encontram no domínio do Clima Subtropical Mesotérmico (Cfa). A colheita nesses municípios, em propriedades próximas, mas dispostas em solos arenosos e argilosos respectivamente visou reduzir as diferenças impostas pelo microclima regional ao produto, procurando acentuar as diferenças geradas pela diversidade do solo.

Destas amostras 15 foram coletadas em solos basálticos e 15 em solos de arenito. A média de altitude dos locais foi de 630 metros para os solos de basalto (valores entre 498 metros e 710 metros acima do nível do mar) e 524 metros para os solos de arenito (valores entre 390 metros e 647 metros acima do nível do mar).

A colheita foi manual e todas as lavouras amostradas adotavam a tecnologia de plantio adensado. Deu-se preferência para os frutos localizados na parte média da planta, e procurou-se colher frutos que estivessem em sua maioria no estágio cereja. A secagem foi ao sol em terreiro convencional localizado em uma das propriedades $\left(23^{\circ} 30^{\prime} \mathrm{S}\right.$ e $\left.51^{\circ} 17^{\prime} \mathrm{W}\right)$ em altitude de $710 \mathrm{~m}$. As amostras em coco, foram estocadas em câmara fria e seca da Universidade Estadual de Londrina (UEL), em Londrina - Pr. 
O beneficiamento foi em descascador de café manual, seguindo-se uma mesma regulagem para todas as amostras, em momentos próximos aos dias de realização das análises, buscando melhor proteção dos grãos durante o armazenamento.

Visando reduzir as características que não estivessem relacionados com as variações impostas pelos solos em estudo (arenito e basalto), foram preparadas duas amostras compostas por meio da mistura de pesos idênticos de café cru de cada uma das propriedades amostradas.

Foram avaliadas as características físicas dos grãos de café cru, para tanto amostras com 300 gramas foram pesadas e separadas manualmente segundo os defeitos, aspecto, cor e seca. Após contagem dos mesmos, utilizou-se o número para equivalência do defeito determinando-se o total de defeitos, classificando o café de acordo com a Tabela Oficial de Santos (BRASIL, 2003).

Após a torra os cafés de cada uma das amostras compostas foram analisados sensorialmente. Para a parcela com torra escura utilizou-se um torrefador elétrico CANHOS, conforme descrito por Schmidt, Miglioranza e Prudêncio (2008), a temperatura final de $210^{\circ} \mathrm{C}$. Próximo ao dia das análises a amostra foi moída em moinho La Cimballi modelo Special na regulagem 6. Para a torra média foram torradas $180 \mathrm{~g}$ de café de cada uma das amostras compostas as quais foram torradas separadamente, por 32 minutos à temperatura $218{ }^{\circ} \mathrm{C}$ em um torrador da marca Pinhalense e moída em moinho La Cimballi modelo Special na regulagem 6. As torras escura e média foram classificadas com base no Sistema Agtron / SCAA Roast Classification Color Disk, onde, Média: discos $n^{\circ} 65$ e 55, Escura: discos n 25 a 45 (STAUB, 19--?).

A avaliação sensorial foi realizada no Laboratório de Análises Físicas e Sensoriais do Instituto de Tecnologia de Alimentos de Campinas (ITAL). A análise sensorial descritiva quantitativa (ADQ®) foi realizada por uma equipe selecionada e treinada composta de oito julgadores, empregando-se escala não estruturada de 0 a $10 \mathrm{~cm}$ para avaliação da fragrância do pó, aroma, defeitos, acidez, amargor, sabor, sabor residual, adstringência e corpo da bebida (HOWELL, 1998), com avaliação final da qualidade global e qualidade do café, conforme terminologia própria (LINGLE, 1986).

As análises foram realizadas individualmente em cabines com iluminação vermelha equipadas com o sistema computadorizado Compusense Five versão 4.8 para coleta dos dados. As amostras apresentadas de forma monádica segundo um delineamento de blocos completos casualizados em esquema fatorial 2 x 2, com código de três dígitos aleatórios e avaliadas em relação a uma amostra de referência sensorial conhecidamente de qualidade Tradicional. De cada amostra foram avaliadas três repetições em uma única sessão. As diferenças entre as médias foram comparadas pelo teste de Scott-Knott $(\mathrm{p}<0,05)$. 
As análises físico químicas foram realizadas com $500 \mathrm{~g}$ das amostras de café cru e com torra escura, obtidas a partir das amostras compostas para cada um dois tipos de material de origem dos solos.

Foram determinadas as variáveis; cinzas, umidade, proteínas, lipídeos, fibras totais, acidez titulável e pH seguindo as normas de análise do Instituto Adolfo Lutz (PREGNOLATTO; PREGNOLATTO, 1985) e índice de coloração (LEITE; CARVALHO, 1994). O delineamento estatístico foi o inteiramente casualizado em esquema fatorial 2 × 2 , com três repetições, as diferenças entre as médias foram pesquisadas pelo Teste de Scott-Knott $(\mathrm{p}<0,05)$.

\section{Resultados e Discussão}

Os resultados de caracterização física dos grãos crus estão apresentados nas Tabelas 1 e 2.

Tabela 1 - Quantificação dos grãos imperfeitos e equivalência em número de defeitos das amostras de café cru.

\begin{tabular}{lcccc}
\hline Solos: & \multicolumn{2}{c}{$\begin{array}{c}\text { Basalto } \\
\text { Equivalência em } \\
\text { Quantidade de grãos } \\
\text { imperfeitos }\end{array}$} & $\begin{array}{c}\text { número de defeitos } \\
\text { Qutos: }\end{array}$ & $\begin{array}{c}\text { Arenito } \\
\text { Equivalência em } \\
\text { número de } \\
\text { defeitos }\end{array}$ \\
\hline Ardido & 20 & 10 & 15 & 7 \\
Casca pequenter de & 0 & 2 & 1 \\
Brocado & 1 & 12 & 18 & 4 \\
Concha & 59 & 0 & 0 & 0 \\
Verde claro & 1 & 2 & 0 & 0 \\
Verde escuro & 10 & 3 & 0 & 0 \\
Quebrado & 5 & 80 & 199 & 40 \\
Chocho/malgranado & 399 & 4 & 1 & 0 \\
Total & 18 & 111 & 225 & 52 \\
\hline
\end{tabular}

As amostras dos cafés provenientes das 15 propriedades localizadas em áreas de solos do tipo basáltico apresentaram o dobro de grãos quebrados e três vezes a quantidade de grãos brocados quando comparados àos provenientes das 15 propriedades localizadas em áreas de solos Arenosos. A quebra maior de grãos colhidos em solos basálticos pode ser atribuída ao tamanho maior desses grãos quando comparados aos colhidos no arenito, pois a regulagem do descascador foi mantida constante.

Os cafés dos solos basálticos, apesar de terem apresentado predominância de grãos maduros, continham 15 grãos verdes, enquanto que no arenoso nenhum grão verde foi encontrado, mas a classificação do tipo dessa amostra foi inferior, quando comparada com o arenito. Uma provável causa seja a maturação mais precoce dos frutos em solos arenosos.

O número de defeitos encontrados para a amostra de café do basalto foi maior, por esse motivo a classificação de tipo foi inferior. Para as demais características avaliadas não foram observadas diferenças entre os cafés. 
A bebida dos dois cafés avaliados foi descrita como dura, com sabor acre, adstringente e áspero, porém sem paladares estranhos. A qualidade com base na avaliação global dos produtos os classificou como cafés tradicionais, com valores entre 4,5 e 6,0 (ABIC, 2004 e 2006).

Tabela 2 - Classificação de amostras de café cru provenientes de solos originados de basalto e arenito Caiuá quanto ao tipo pelo número de defeitos, cor do grão, aspecto e seca.

\begin{tabular}{lllll}
\hline Amostras & Tipo & Cor do grão & Aspecto & Seca \\
\hline Basalto & $6-15$ & Esverdeado & Regular & Boa \\
Arenito & $5-10$ & Esverdeado & Regular & Boa \\
\hline
\end{tabular}

As notas médias recebidas pelos cafés colhidos nas formações Serra Geral e Caiuá, para qualidade global, foram de 4,72 e 4,88 respectivamente, na torra média feita dentro da faixa de 45 a 75 Agtron, recomendada pela ABIC para essa determinação. Os demais resultados das análises sensoriais podem ser encontrados na Tabela 3.

Tabela 3 - Resultados dos testes sensoriais realizados por equipe treinada, com amostras de cafés da formação Caiuá e Serra Geral colhidos no estágio cereja, secos em terreiro e com dois pontos de torra.

\begin{tabular}{lcccc}
\hline \multirow{2}{*}{ Atributos } & \multicolumn{2}{c}{ Torra média } & \multicolumn{2}{c}{ Torra escura } \\
\cline { 2 - 5 } & Arenito & Basalto & Arenito & Basalto \\
\hline Fragrância & $5,96^{\mathrm{Aa}}$ & $6,13^{\mathrm{Aa}}$ & $5,73^{\mathrm{Aa}}$ & $5,61^{\mathrm{Ba}}$ \\
Aroma & $4,95^{\mathrm{Ba}}$ & $5,02^{\mathrm{Aa}}$ & $4,60^{\mathrm{Aa}}$ & $4,22^{\mathrm{Ba}}$ \\
Defeitos & $5,09^{\mathrm{Ba}}$ & $5,01^{\mathrm{Ba}}$ & $5,48^{\mathrm{Aa}}$ & $5,54^{\mathrm{Aa}}$ \\
Acidez & $1,88^{\mathrm{Aa}}$ & $1,87^{\mathrm{Aa}}$ & $1,74^{\mathrm{Aa}}$ & $1,74^{\mathrm{Aa}}$ \\
Amargor & $5,25^{\mathrm{Aa}}$ & $5,08^{\mathrm{Ba}}$ & $5,45^{\mathrm{Aa}}$ & $5,60^{\mathrm{Aa}}$ \\
Sabor & $4,78^{\mathrm{Aa}}$ & $4,80^{\mathrm{Aa}}$ & $4,56^{\mathrm{Aa}}$ & $4,39^{\mathrm{Ba}}$ \\
Sabor residual & $4,82^{\mathrm{Aa}}$ & $4,51^{\mathrm{Ba}}$ & $4,36^{\mathrm{Ba}}$ \\
Adstringência & $4,80^{\mathrm{Aa}}$ & $4,99^{\mathrm{Ba}}$ & $5,29^{\mathrm{Aa}}$ & $5,37^{\mathrm{Aa}}$ \\
Corpo & $5,20^{\mathrm{Aa}}$ & $5,70^{\mathrm{Aa}}$ & $5,83^{\mathrm{Aa}}$ & $5,85^{\mathrm{Aa}}$ \\
Qualidade global & $5,76^{\mathrm{Aa}}$ & $4,88^{\mathrm{Aa}}$ & $4,45^{\mathrm{Ba}}$ & $4,32^{\mathrm{Ba}}$ \\
\hline
\end{tabular}

Obs. Letras minúsculas indicam diferença significativa entre os solos de texturas diferentes em cada uma das torras e letras maiúsculas indicam diferença entre torras diferentes. Atributos avaliados em pontos, segundo escala de 0 a 10 pontos.

Ao se comparar esses resultados com os obtidos por Aguiar et al., (2001), percebe-se que a acidez foi menor e que variou entre 2,17 a 3,96, para as sete cultivares por eles estudadas, porém os cafés avaliados por eles foram despolpados e os do presente estudo foram café secos em terreiro obtendo-se café natural. Segundo MORI et al., (2001), os cafés tipo natural possuem média acidez apresentando sabor doce, e os despolpados apresentam menor acidez e alguma doçura. Por esse motivo, os baixos valores de acidez sensorial confirmados pelos valores de acidez titulável e $\mathrm{pH}$ obtidos (Tabela 4), não eram esperados.

Aguiar et al., (2001), encontrou valores para corpo entre 4,41 e 5,7, o que nos leva a observar que os cafés aqui avaliados (Tabela 3) podem ser considerados tão encorpados quanto os 
mais encorpados daquele estudo. Os cafés naturais são de acordo com MORI et al., (2001); muito encorpados com forte aroma, já os despolpados apresentam bom corpo e aroma.

Para atributos como: fragrância, aroma, amargor, sabor, sabor residual e qualidade global os valores de Aguiar et al., (2001) foram mais elevados. Esperava-se maiores valores de notas para aroma devido tratar-se de café natural.

Não foram observadas diferenças estatisticamente significativa entre os atributos sensoriais avaliados para ambas as amostras compostas em uma mesma torra. O que mostra uma semelhança sensorial entre os cafés apesar de terem sido colhidos em solos de origem distinta, sugerindo a possibilidade de se produzir cafés com a mesma qualidade nessas diferentes formações de solos do Paraná.

De modo geral a torra escura levou ao aumento do amargor, da adstringência e dos defeitos e, reduziu o sabor, a acidez, o aroma e fragrância do produto e, com base nessas alterações pode-se justificar que as torras escuras não são indicadas para análise descritiva do café. Torras mais claras são recomendadas pela ICO (1991) devido preservarem o aroma de ervas e frutas e a acidez, que são reduzidas por torras mais escuras, que também aumentam características como amargor, o aroma de queimado e fumaça.

Para os cafés de solos de textura arenosa, foram observadas diferenças significativas para aroma, defeitos, sabor residual e qualidade global, nas diferentes torras. Para os de solo de textura argilosa, percebe-se diferenças significativas para fragrância, aroma, defeitos, amargor, sabor, sabor residual, adstringência e qualidade global, nas diferentes torras.

Os resultados das análises físico-químicas do café cru e com torra escura, são visualizados na Tabela 4. Os teores de umidade, cinzas e lipídeos do café torrado situaram-se dentro dos parâmetros mínimos estabelecidos pela legislação para o produto (BRASIL, 1999). Os valores observados para proteínas, pH, acidez titulável e índice de coloração, foram próximos dos apresentados por Machado et al., (2007), para diferentes marcas de cafés comerciais.

Os resultados das análises bromatológicas do café cru ficaram próximos de valores apresentados por Dal Molin et al., (2007) em cafés 'IAPAR 59', cultivados em Jesuítas - Paraná, localizada em solos da formação Serra Geral de origem Basáltica. Enquanto que valores de umidade e lipídeos foram inferiores aos valores mínimos obtidos por aqueles autores, e os de proteínas e acidez titulável semelhantes.

Com exceção do $\mathrm{pH}$ todas as demais análises físico-químicas foram significativamente alteradas pela torra, encontrou-se diferença estatisticamente significativa ao nível de 5\% entre todas elas o que pode ser visualizado na Tabela 4 observando-se as letras maiúsculas. 
Tabela 4 - Teores físico-químicos médios encontrados no café cru e no café com torra escura.

\begin{tabular}{ccccccc}
\hline & \multicolumn{2}{c}{ Café Cru } & & \multicolumn{2}{c}{ Café Torra Escura } \\
\cline { 2 - 3 } \cline { 5 - 6 } Análises Realizadas & Arenito & Basalto & & Arenito & Basalto \\
\hline Umidade & $7,97^{\mathrm{bA}}$ & $8,40^{\mathrm{aA}}$ & & $1,80^{\mathrm{aB}}$ & $1,80^{\mathrm{aB}}$ \\
Fibra Bruta & $32,31^{\mathrm{aA}}$ & $30,76^{\mathrm{aA}}$ & & $20,45^{\mathrm{bB}}$ & $24,66^{\mathrm{aB}}$ \\
Cinzas & $4,14^{\mathrm{aB}}$ & $3,90^{\mathrm{bB}}$ & & $4,88^{\mathrm{aA}}$ & $4,67^{\mathrm{bA}}$ \\
Proteína & $14,32^{\mathrm{aA}}$ & $13,12^{\mathrm{aA}}$ & & $16,32^{\mathrm{aA}}$ & $14,10^{\mathrm{bA}}$ \\
Lipideos & $5,69^{\mathrm{bB}}$ & $6,31^{\mathrm{aB}}$ & & $10,74^{\mathrm{aA}}$ & $10,00^{\mathrm{aA}}$ \\
Carboidratos & $67,71^{\mathrm{aA}}$ & $68,28^{\mathrm{aA}}$ & & $66,27^{\mathrm{bA}}$ & $67,79^{\mathrm{aA}}$ \\
Acidez titulável & $112,7^{\mathrm{aA}}$ & $110,3^{\mathrm{aA}}$ & & $88,9^{\mathrm{aB}}$ & $83,9^{\mathrm{bB}}$ \\
pH & $6,43^{\mathrm{aB}}$ & $6,61^{\mathrm{aA}}$ & & $6,87^{\mathrm{aA}}$ & $6,37^{\mathrm{bB}}$ \\
Índice de coloração & $0,427^{\mathrm{aB}}$ & $0,396^{\mathrm{aB}}$ & & $1,255^{\mathrm{aA}}$ & $1,247^{\mathrm{aA}}$ \\
\hline
\end{tabular}

Obs. Umidade, cinzas, proteínas, lipídeos, fibras e carboidratos (valores calculados por diferença) expressos em (\% b.s.), acidez titulável em mL de $\mathrm{NaOH} 0,1 \mathrm{~N} \cdot 100 \mathrm{~g}^{-1}$. Letras minúsculas indicam diferença significativa entre produtos iguais em solos de texturas diferentes e letras maiúsculas indicam diferença entre o produto cru e torrado.

Houve diferença estatisticamente significativa ao nível de $5 \%$ entre as umidades dos cafés crus, uma possível explicação seria a secagem em terreiro, a qual geralmente não é capaz de uniformizar esses teores de umidade. Após a torra os teores de umidade foram reduzidos para 1,8\% o que segundo Trugo (1987) corresponde a uma torra escura, o que também foi verificado pela leitura realizada no disco de Angtron que resultou em valor 25.

A fibra bruta é constituída principalmente de celulose, lignina e hemicelulose, componentes responsáveis pela sustentação. No entanto, estudos sobre a influência destes polissacarídeos na qualidade são praticamente inexistentes (PEREIRA, 1997). A composição mineral do grão é influenciada pelo estado nutricional do cafeeiro, interagindo com o local de cultivo e a variedade do café (AMORIM, 1968).

No presente estudo não se verificou diferença significativa entre as amostras para os teores de fibras em café cru. Após a torra, o teor de fibra da amostra proveniente do arenito foi significativamente menor que o da originada do basalto.

Os grãos de café sadios têm apresentado teores de minerais inferiores aos grãos defeituosos. Valores na faixa de 5 a $6 \%$ têm sido relatados para grãos defeituosos (VASCONCELOS et al., 2005). Nesse trabalho, os grãos crus provenientes do basalto apresentaram valores estatisticamente diferentes e menores de cinzas que o encontrado para os grãos provenientes dos solos arenosos, porém ambos ficaram dentro da faixa descrita para cafés sadios.

Os valores de cinzas encontrados no café após a torra também foram significativamente menores que os encontrados para o arenito.

Cafés de qualidade superior apresentam maiores teores de proteína solúvel e aminoácidos livres (AMORIM, 1978). A tendência da amostra de café produzido no arenito, submetido a um clima mais quente, foi de aumento no teor de proteínas dos grãos; mas, essa diferença não foi estatisticamente significativa ao nível de $5 \%$ para o café cru. 
Esse comportamento já foi confirmado para soja por Gonçalves (2002), que comprovou que o conteúdo total de proteínas nas sementes de soja foi maior em temperaturas ambientes elevadas durante a fase de enchimento dos grãos, porém não foram encontrados estudos com o café.

No café, as proteínas estão livres no citoplasma ou ligadas a polissacarídeos da parede celular, sendo completamente desnaturadas durante a torra. As proteínas são fontes da maioria dos flavors característicos do café; com a torra, essas se desnaturam em temperaturas inferiores à da pirólise, ocorrendo hidrólise das ligações peptídicas das moléculas protéicas com liberação de aminas e carbonilas (SIVETZ e DESROISIER, 1979). Muitos destes voláteis formados por essas reações são de grande importância para o aroma e qualidade do café torrado (TRESSL e SILWAR, 1981). No presente trabalho o aroma avaliado pela análise sensorial na torra escura mostrou uma correlação forte com o teor de proteínas, o coeficiente de correlação linear de Pearson foi de 80,4\%.

Valores de extrato etéreo entre 4,91 e 11,12\% foram encontrados por FERNADES et al. (2001), para grãos crus de café arábica em diferentes safras, o que sugere que a safra pode alterar o teor desse componente nos grãos. Valores entre 5 e $6 \%$ de óleo em grãos verdes e entre 9 e $11 \%$ em café torrado também são relatados por LAGO et al. (2001). Neste estudo os valores foram próximos aos menores encontrados por esses autores (Tabela 2).

Segundo LERCKER et al. (1996), o teor de lipídios aumenta após a torra devido, sobretudo, à destruição de carboidratos durante o processamento térmico. Em seu trabalho com café arábica, os teores passaram de 11,4 para $15,4 \%$, e em robusta passaram de 6,1 para 9,6\%, resultando em um percentual de aumento de aproximadamente 4\%, o que também pode ser verificado no presente estudo (Tabela 4).

Os teores de carboidratos mostraram tendência de redução após a torra, entretanto as diferenças não foram significativas para nenhuma das amostras. Algumas proteínas reagem com carboidratos por meio da reação de Maillard e também com compostos fenólicos (TRESSL e SILWAR, 1981).

O teor médio de lipídeos obtido para os grãos de café cru foi significativamente maior para a amostra proveniente do basalto. A maior concentração de lipídeos nos bordos externos dos grãos de cafés de melhor qualidade favorecem a maior retenção do aroma, melhorando assim a qualidade do produto (AMORIM, 1978; AGUIAR et. al., 2005). As notas dadas pela equipe sensorial (Tabela 3) para o aroma da torra média indicada para esse teste mostrou valores maiores para a amostra proveniente do basalto, apesar de não ter sido observada diferença significativa.

Pesquisadores sugerem que a acidez total é que apresenta melhor correlação para determinar a acidez do café (VOILLEY et al., 1981), já o pH tem sido correlacionado com a acidez perceptível (SIVETZ e DESROSIER, 1979), por isso, tem sido estudado como forma de avaliação deste importante atributo sensorial. 
Ao se correlacionar as notas dadas para acidez na análise sensorial deste trabalho com os valores de $\mathrm{pH}$ medidos nos produtos obtivemos correlação positiva e moderada, pois o coeficiente de correlação linear de Pearson foi de 43,3\%. Os valores aqui encontrados para 'IAPAR 59' estiveram próximos dos encontrados por Lopes et al., (2000), ao estudarem sete cultivares de café cujos valores de $\mathrm{pH}$ situaram-se entre 6,39 e 6,62.

Cafés de melhor qualidade possuem, segundo Leite (1991) e Carvalho et al,. (1994) menor acidez titulável total e maior índice de coloração. Nesse trabalho os valores de acidez titulável e índice de coloração foram menores que os comumente encontrados na literatura, mas pôde-se perceber uma forte correlação negativa entre a acidez titulável e o índice de coloração, pois o coeficiente de correlação linear de Pearson foi de $-97,5 \%$.

Os valores de índice de coloração obtidos sugerem que as amostras de café aqui estudadas passaram por um período de amontoa com conseqüente fermentação, tendo em vista que os valores para as duas amostras se apresentaram menores que os citados por Pimenta e Vilela (2001) para sete dias de fermentação.

Em faixas de temperatura média mais elevada, os cafés apresentam teores de acidez menores segundo Androcioli Filho et al., (2003), o que pode justificar os valores encontrados para o pH e acidez titulável dos cafés avaliados nesse estudo.

A atividade da enzima polifenoloxidase não foi avaliada nesse estudo, mas ela tem sido descrita como um atributo de qualidade do café e o seu aumento tem sido correlacionado com uma redução da acidez, havendo, portanto, uma relação inversa (LEITE, 1991; CARVALHO et al., 1994; CHAGAS, 1994), a acidez do café avaliado foi baixa indicando boa qualidade dos produtos aqui estudados.

\section{Conclusão}

A diferenciação dos cafés estudados ocorreu em termos qualitativos apenas em relação à classificação por tipo.

As diferenças físico-químicas encontradas foram muito pequenas e sensorialmente os cafés receberam as mesmas classificações de bebida dura e café tradicional.

O teor médio de lipídeos foi menor no café produzido no arenito. Os cafés, da cultivar IAPAR 59, apresentaram atributos qualitativos semelhantes, bom corpo e baixa acidez.

\footnotetext{
Abstract

The logistic of commercialization of the Parana State, the similarity that occurs with the producing regions of wine, suggest that the coffee produced in the state is separated as its region of origin. Which one characterizes the Paraná coffee production, is the fact that it is implanted in soil of
} 
basaltic origin and deriving soil of the Caiuá sandstone. This study was developed searching the characterization physical-chemical of the grains and sensorial of drinks of the coffees produced in basaltic and sedimentary soil. Cultivating IAPAR 59 samples were evaluated, being carried through the analyses: classification of type, leached ashes, humidity, proteins, lipids, staple fibres, titratable acidity, $\mathrm{pH}$ and coloration index. The quantitative descriptive analysis (ADQ®), made by eight trained tasters, for two samples composed of grains harvested in arenaceous and argillaceous soils with two intensities of roasting, getting scores in scale of one to ten for attributes as: fragrance, aroma, defects, acidity, bitter taste, flavor, residual flavor, astringency, body and global quality. The trained tasters did not detect differences between the coffees deriving of different formations of soils in any of the intensities of roasting. In the dark roasting, the tasters detected increase in the bitter taste and in the astringency, and reduction in the flavor, acidity, aroma and fragrance. Independently of the texture or origin of the soils the coffees showed good body and low acidity. The lipids level was lower in the coffee produced in the sandstone.

Key-words: Coffea Arabica; nitossol; marketing; drink quality.

\section{Referências}

ABIC. Guia prático do programa de qualidade do café - PQC. 1ed. nov. 2004. Disponível em: <http://www.abic.com.br/gar_qualidade.html>. Acesso em: 12 set. 2010.

ABIC. Programa de qualidade do café (PQC): Passo a Passo. 2006. Disponível em: 〈http://www.abic.com.br/arquivos/pqc_passoapasso_abr06.pdf >. Acesso em: 12 set. 2010.

AEN. Produção de café no Paraná será 56\% maior do que ano passado. Agência Estadual de Notícias, 13 mai. 2006. Disponível em: <http://www.agenciade noticias.pr.gov.br/modules/news/article.php?storyid=20612>. Acesso em: 20 jan. 2010.

AGUIAR, A. T. E.; MALUF, M. P.; GALlO, P. B.; MORI, E. E. M.; FAZUOLI, L. C.; GUERREIRO-FILHO, O. Análise sensorial da bebida das cultivares Ouro verde, Tupi e Obatã. In: SIMPÓSIO BRASILEIRO DE PESQUISA DOS CAFÉS DO BRASIL, 2., 2001, Vitória. Anais... Brasília: EMBRAPA Café, 2001, p. 1242-1247. CDROM.

AGUIAR, A. T. E.; SALVA, T. de J. G., FAZUOLI, L. C.; FAVARIN, J. L. Variação no teor de lipídios em grãos de variedades de Coffea canephora. Pesquisa Agropecuária Brasileira, v. 40, n. 12, p. 1251-1254, 2005. http://dx.doi.org/10.1590/S0100-204X2005001200015

AIRES, U. Café: Cocamar quer mostrar que é possível atenuar o ciclo bianual. Sindicato Rural de Maringá. Notícia de 05 de mar. 2007. Disponível em: <http://www.sindrural.com.br/content/view/615/151/>. Acesso em: 24 dez. 2009.

AMORIM, H. V. Aspectos bioquímicos e histoquímicos do grão de café verde relacionados com a deterioração da qualidade do café. 1978. Tese (Livre Docência em Bioquímica) - Escola Superior de Agricultura "Luiz de Queirós", Piracicaba. $85 \mathrm{p}$.

AMORIM, H. V.; SILVA, O. M. Relationship between the polyfenoloxidase activity of coffee beans and quality of the beverage. Nature, v. 219, n. 5152, p. 381-382, 1968. http://dx.doi.org/10.1038/219381a0

ANDROCIOLI FILHO, A.; LIMA, F. B.; TRENTO, É. J.; CARNEIRO FILHO, F.; CARAMORI, P. H.; SCHOLZ, M. B. do S. Caracterização da qualidade da bebida dos cafés produzidos em diversas regiões do Paraná. In: SIMPÓSIO DE PESQUISA DOS CAFÉS DO BRASIL E WORKSHOP INTERNACIONAL DE CAFÉ \& SAÚDE: 3., 2003, Porto Seguro. Anais... Brasília: EMBRAPA Café, 2003. (447p.), p. 256-257

BRASIL. Portaria n ${ }^{\circ} 377$, de 26 de abril de 1999. Estabelece normas para fixar a identidade e as características mínimas de qualidade do café torrado em grão e café torrado e moído. Diário Oficial [da] República Federativa do Brasil, Brasília, 29 abr. 1999, n.80-E, Seção 1. Disponível em: 〈www.anvisa.gov.br/legis/portarias/377_99.htm>. Acesso em: 20 jan. 2008.

BRASIL. Instrução Normativa $\mathrm{n}^{\circ}$ 08, de 11 de junho de 2003. Estabelece normas para fixar a identidade e a qualidade na classificação do café beneficiado grão cru. Diário Oficial [da] República Federativa do Brasil, Brasília, 13 jun. 2003, p.4, Seção 1. Disponível em: 〈http://www.pr.gov.br/claspar/pdf/cafebenef008_03.pdf〉. Acesso em: 14 dez. 2008. 
CARVALHO, V. D. de; CHAGAS, S. J. de R.; CHALFOUN, S. M.; BOTREL, N.; JUSTE JUNIOR, E. S. G. Relação entre a composição físico-química e química do grão beneficiado e a qualidade de bebida do café. 1. Atividade de polifenoloxidase e peroxidase, índice de coloração e acidez. Pesquisa Agropecuária Brasileira, v. 29, n. 3, p. 449-454, 1994.

CHAGAS, S. J. R. Caracterização química e qualitativa de cafés de alguns municípios de três regiões produtoras de Minas Gerais. 1994. Dissertação (Mestrado em Ciência de Alimentos) - Universidade Federal de Lavras, Lavras. 95p.

DALBERTO, F.; ANDROCIOLLI FILHO, A.; SCHIMITH, S.; CARNEIRO FILHO, F. Café do Paraná: mais um dos bons Cafés do Brasil. Informativo Garcafé, Garça: Cooperativa dos Cafeicultores da Região de Garça, março de 2000.

DAL-MOLIN, R. N.; SCHOLZ, M. B. S.; SCARMINIO, I. S.; ANDREOTTI, M. BRAGA, G. C.; OLIVEIRA, M. C.; SILVA, R. S. F.; GUYOT, B.; RIBEYRE, F.;DAVRIEUX, F. Composição química do café produzido nas condições topoclimáticas de Jesuítas, Paraná. In: SIMPÓSIO BRASILEIRO DE PESQUISA DOS CAFÉS DO BRASIL, 5., 2007, Águas de Lindóia. Anais... Brasília: EMBRAPA Café, Campinas: Instituto Agronômico de Campinas, Belo Horizonte: MINASPLAN, 2007. CDROM.

EMBRAPA. Levantamento de Reconhecimento dos Solos do Estado do Paraná. Boletim de Pesquisa, n.27. Curitiba: Empresa Brasileira de Pesquisa Agropecuária - Serviço Nacional de Levantamento e Conservação de Solos Superintendência do Desenvolvimento da Região Sul - Instituto Agronômico do Paraná, 1984. 196p. 2t.

FERNADES, S. M.; PEREIRA, R. G.; NERY, F.; PINTO, N. A. V. Caracterização da composição química de arábica e conillon. In: SIMPÓSIO BRASILEIRO DE PESQUISA DOS CAFÉS DO BRASIL, 2., 2001, Vitória. Anais... Brasília: EMBRAPA Café, 2001. CDROM.

GASPARETTO, V. L. N., SOUZA, L. M. Contexto geológico-geotécnico da Formação Caiuá no Terceiro Planalto Paranaense - Pr. In: ENCONTRO GEOTÉCNICO DO TERCEIRO PLANALTO PARANAENSE, 1., 2003, Maringá. Anais... Maringá: Universidade Estadual de Maringá, 2003. CDROM.

GONÇALVES, C. A. Influencia da temperatura no acúmulo de proteínas de reserva em sementes de soja. Dissertação (Mestrado em Fisiologia Vegetal) - Universidade Federal de Viçosa, Viçosa. 2002. 29p.

HOWELL, G. SCAA Universal Cupping Form \& How to use it. In: ANNUAL CONFERENCE \& EXHIBITION "PEAK OF PERFECTION"- PRESENTATION HANDOUTS, 10., 1998, Denver. Anais... Denver: Specialty Coffee Association of America, Abr. 17-21, 1998. (ANEXO B).

ICO. Sensory study of the effect of degree of roast and brewing formula on the final cup characteristics. International Coffee Organization. Technical Unit. Quality Series. Report n.7. London, 1991. 16p.

LAGO, R. C. A.; ANTONIASSI, R.; FREITAS, S. C. de. Composição centesimal e de aminoácidos de café verde, torrado e de borra de café solúvel. In: SIMPÓSIO BRASILEIRO DE PESQUISA DOS CAFÉS DO BRASIL, 2., 2001, Vitória. Anais... Brasília: EMBRAPA Café, 2001. p. 1473-1478. CDROM.

LEITE, I. P. Influência do local de cultivo e do tipo de colheita nas características físicas, composição química do grão e qualidade do café (Coffea arábica L.). 1991. Dissertação (Mestrado em Ciência dos Alimentos) - Universidade Federal de Lavras, Lavras. 131p.

LEITE, I. P.; CARVALHO, V. D. Influência do local de cultivo e do tipo de colheita nas características físicas, composição química do grão e qualidade do café.I - atividade da polifenoloxidase, proteína do extrato enzímico e índice de coloração. Pesquisa Agropecuária Brasileira, v. 29, n. 2, p. 299-308, 1994.

LERCKER, G.; CABONI, M. F.; BERTACCO, G.; TURCHETTO, E.; LUCCI, A.; BORTOLOMEAZZI, R.; PAGANI, E.; FREGA, N.; BOCCI, F. La frazione lipidica del caffè. Nota 1: Influenza della torrefazione e della decaffeinizzazione. Industrie Alimentari, v. 35, n. 10, p. 1057-1065, 1996.

LEROY, T.; RIBEYRE, F.; BERTRAND, B.; CHARMETANT, P.; DUFOUR, M.; MONTAGNON, C; MARRACCINI, P.; POT, D. Genetics of coffee quality. Brazilian Journal of Plant Physiology, v. 18, n. 1, 2006. http://dx.doi.org/10.1590/S1677-04202006000100016

LINGLE, T. R. The coffee cupper's handbook: Systematic Guide to the Sensory Evaluation of Coffee's Flavor. 2.ed. Washington: Coffee Development Group, 1986. 57p. 
LOPES, L. M. V.; PEREIRA, R. G. F. A.; MENDES, A. N. G. Teor de sólidos solúveis totais, acidez total titulável e pH de grãos crus e torrados de sete cultivares de café (Coffea arabica L.) e suas variações como o processo de torração. In: SIMPÓSIO DE PESQUISA DOS CAFÉS DO BRASIL, 1., 2000, Poços de Caldas. Anais... Brasília: EMBRAPA Café; Belo Horizonte: MINASPLAN, 2000b. v.2., p.748-751. 1490p.

MACHADO, R. A.; MENDONÇA, L. M. V. L.; SANDI, A. L. S.; FIRMINO, R. J. S. ARAÚJO, F. P. Avaliação bromatológica de diferentes marcas de cafés torrados e moído comercializados no município de Muzambinho - Minas Gerais. In: SIMPÓSIO BRASILEIRO DE PESQUISA DOS CAFÉS DO BRASIL, 5., 2007, Águas de Lindóia. Anais... Brasília: EMBRAPA Café, Campinas: Instituto Agronômico de Campinas, Belo Horizonte: MINASPLAN, 2007. CDROM.

MITIDIERI, F. J. Nota técnica. Diário Oficial [da] República Federativa do Brasil, Brasília, 10 ago. 2007, n.154, Sessão 1. Disponível em: <http://www.in.gov.br/ materias/pdf/do/secao1/10_08_2007/do1-4.pdf〉. Acesso em: 27 dez. 2008.

MORI, E. E. M.; BRAGAGNOLO, N.; MORGANO, M. A.; ANJOS, V. D. A.; YOTSUYANAGI, K.; FARIA, E. V.; IYOMASA, J. M. Brazil Coffee Growing Regions and Quality of Natural, Pulped Natural and Washed Coffees. In: INTERNATIONAL COFERENCE ON COFFEE SCIENCE, 19., 2001, Trieste. Anais... Trieste: Association Scientifique Internationale du Café (ASIC), 14-18 mai. 2001. CDROM.

MOTOKI, A.; ZUCCO, L. L.; VARGAS, T.; NEVES, J. L. P. Basalto da Serra Gaúcha e sua Relação com o Desenvolvimento Regional. In: CONGRESSO BRASILEIRO DE EXTENSÃO UNIVERSITÁRIA, 2., 2004, Belo Horizonte. Anais... Belo Horizonte: Universidade Federal de Minas Gerais, 12 a 15 set. 2004. CDROM.

MULLER, N. L. Contribuição ao Estudo do Norte do Paraná. Geografia, Londrina, v.10, n.1, p.89-118, 2001.

MUZILLI, O. Degradação e recuperação do solo sob uso agrícola: o caso do estado do Paraná. Londrina: Instituto Agronômico do Paraná - Área Técnica de Solos. Disponível em: <http://www.cemacufla.com.br/trabalhospdf/Palestras/Palestra\%20Osmar\%20Muzilli.pdf>. Acesso em: 10 out. 2010.

NAKASHIMA, P.; NÓBREGA, M. T. Solos do terceiro planalto do Paraná: Brasil. In: I ENCONTRO GEOTÉCNICO DO TERCEIRO PLANALTO PARANAENSE, 1.,2003, Maringá. Anais... Maringá: ENGEOPAR, 2003. p.67-85. CDROM.

NARDY, A. J. R.; SQUISATO, E.; MACHADO, F. B.; OLIVEIRA, M. A. F. de. Os derrames básicos da borda leste da bacia do Paraná no estado de São Paulo: considerações preliminares. In: SIMPÓSIO DE VULCANISMO E AMBIENTES ASSOCIADOS, 3., 2005, Cabo Frio. Anais... Rio de Janeiro: Universidade Estadual do Rio de Janeiro. São Paulo: Sociedade Brasileira de Geologia, 02 a 07 ago. 2005. CDROM.

O CAFEZAL. Paraná: relevo acidentado requer trabalho manual. Coffee Break. Garça: Texturando. Disponível em: <http://coffeebreak.com.br/ocafezal.asp? SE=6\&ID=40>. Acesso em: 25 jan. 2008.

PEREIRA, R. G. F. A. Efeito da inclusão de grãos defeituosos na composição química e qualidade do café (Coffea arabica L.). Lavras: UFLA, 1997. 96p.

PIMENTA, C. J.; VILELLA, E. R. Qualidade do Café (Coffea arabica L.), lavado e submetido à diferentes tempos de amontoa no terreiro. Revista Brasileira de Armazenamento, v. especial, n. 2, p. 3-10, 2001.

PREGNOlatto, W.; PREGnOlatTO, N. P. Normas analíticas do Instituto Adolfo Lutz. 3.ed. São Paulo: Instituto Adolfo Lutz, 1985.

SCHMIDT, C. A. P.; MIGLIORANZA, E.; PRUDENCIO, S. H. Interação da torra e moagem do café na preferência do consumidor do oeste paranaense. Ciência Rural, v. 38, n. 4, 2008.

SERA, T.; ANDROCIOLI FILHO, A.; CARDOSO, R. M. L.; DIAS, M. C. L. L.; GUERREIRO, E.; SILVA, E. IAPAR 59 - cultivar de café para plantio adensado. In: SIMPÓSIO INTERNACIONAL SOBRE CAFÉ ADENSADO, 1., 1994, Londrina. Anais... Londrina: Instituto Agronômico do Paraná, 1994. p.293-294.

SIVETZ, M.; DESROSIER, N. W. Physical and chemical aspects of coffee. In: Coffee Technology. Westport: AVI Publishing Company, p. 527-575, 1979. 
STAUB, C. Agtron/ SCAA Roast Classification - Color Disk System. Chicago: Specialty Coffee Association of America. Nota científica, [19--?].

TRESSL, R.; SILWAR, R. Investigation of sulfur-containing components in roasted coffee. Journal of Agriculture and Food Chemintry, v. 29, n. 5, p. 1078-1082, 1981. http://dx.doi.org/10.1021/jf00107a045

TRUGO, L. C. Efeito da torrefação no perfil cromatográfico obtido por filtração em gel de extratos de café arábica. Archivos Latinoamericanos de Nutrición, v. 36, n. 4, p. 745-753, 1987.

VASCONCELOS, A. L. S.; FRANÇA, A. S.; OLIVEIRA, L. S.; GLÓRIA, M. B. A. Avaliação comparativa da composição centesimal de grãos defeituosos e sadios de café. In: SIMPÓSIO DE PESQUISA DOS CAFÉS DO BRASIL, 4., 2005, Londrina. Anais... Brasília: EMBRAPA Café, 2005. CDROM.

VOILLEY, A.; SAUVAGEOT, F.; SIMATOS, D.; WOJCIK, G. Influence of some processing conditions on the quality of coffee brew. Journal Food Processes Preservation, v. 5, n. 3, p. 135-143, 1981. http://dx.doi.org/10.1111/j.17454549.1981.tb00629.x

Submetido em 03 jan 2011, Aceito para publicação em 21 mai. 2012. 